\title{
Inquietud, costumbre y Absoluto. Principio y fin del deseo en Pascal y Agustín de Hipona ${ }^{1}$
}

\section{(Restlessness, Habit and Absolute. Beginning and End of Desire in Augustine and Pascal)}

\author{
Diego I. Rosales Meana
}

Recibido: 21 de febrero de 2013

Aceptado: 7 de octubre de 2013

\section{Resumen}

En este trabajo intentaré mostrar que, de acuerdo con Agustín de Hipona -y a diferencia de una cierta lectura relativamente clásica de Pascal-, el deseo puede ser el comienzo de la relación del hombre con el Absoluto. Para ello divido el texto en cuatro partes: primero, describo la situación existencial primordial de la que nace el deseo, la inquietud. Después, describo el doble despliegue del deseo: amor o concupiscencia, según objeto e inclinación. En tercer lugar, intento describir los tipos de concupiscencias y sus paralelismos en ambos autores. Concluyo mostrando la importancia de la costumbre en la constitución del deseo.

Palabras clave: Agustín de Hipona, Pascal, amor, costumbre, deseo, libido.

\begin{abstract}
The aim of this text is to show that, according to Augustine of Hippo -and in contrast to a relatively classic lecture of Pascal-, desire can be de beginning of the relation between man and the Absolute. I will divide the work into four parts: first I will describe the existential situation in which desire is born: restlessness. In second place I will describe the development of desire: as love or as concupiscence, according to its object and inclination. In third place I will try to describe the types
\end{abstract}

\footnotetext{
${ }^{1}$ Debo agradecer a la prof. a Alicia Villar por la primera motivación fundamental para realizar este trabajo y por sus didácticos comentarios, que me ayudaron a concebir lo que de bueno haya aquí.
} 
of concupiscence and their parallelism in both authors. I conclude showing the importance of habit in the constitution of desire.

Keywords: Augustine of Hippo, Pascal, love, desire, libido, habit.

\section{Introducción}

Cuando en el hombre resuena la pregunta por el sentido de su propia vida, lo que en realidad está resonando es la constatación patente de su propia libertad. Esa libertad no hace otra cosa que presentar frente a los ojos de cada hombre su constante posibilidad de ser ejercida. Si la vida humana es siempre posibilidad y capacidad de afirmación, la alternativa se nos presenta no solamente como la elección positiva de una de las opciones, sino también como el rechazo de otras tantas. Por eso no da igual cómo se viva la vida. Y, en efecto, no es lo mismo una vida dedicada a la cultura y al arte que una vida dedicada a los negocios. Pero tampoco da igual una vida dedicada a atender el sufrimiento del otro que una vida a la que no le importa qué tan canalla pueda ser en su carrera por triunfar en el mundo. Cuando una persona concibe estas diferencias se sitúa en la encrucijada existencial que le obliga a elegir y que le obliga, además, a elegir lo mejor. Esta situación dramática representa el centro de la vida de los hombres una vez constatado que la vida la hace uno.

Bajo esta tesitura, los deseos que surgen desde el fondo de nuestra alma cobran una importancia tremenda pues, ni podemos simplemente acallarlos y hacer oídos sordos a su exigencia, ni tampoco podemos escucharlos y darles cauce a todos sin algún tipo de separación respecto de ellos desde la cuál juzguemos su pertinencia, oportunidad y bondad. El deseo es el primer acicate, pues, la primera flecha de la ballesta de la vida que mueve al hombre a perseguir su felicidad, aunque no sepa bien a bien en dónde ha de encontrar la diana.

Frecuentemente nuestros deseos se presentan como la oportunidad de la realización plena de un gran anhelo de felicidad, de beata vita. Pero, otras veces, son ellos mismos la ocasión de nuestra misma perdición, del alejamiento terrible de esa vida bienaventurada y el abismamiento en la más profunda de las desesperaciones. En este trabajo me propongo profundizar en el drama de la existencia humana desde algunos textos de Agustín de Hipona y desde la lectura que de ellos, ya en los albores de la Modernidad hizo Blaise Pascal.

A partir de la lectura que hizo Pascal de San Agustín, y sobre todo considerando algunos énfasis retóricos del pensador francés, se forjó una tradición que, creyéndose plenamente agustiniana, condenó al deseo como mera concupiscencia y fuente del mal moral. No obstante, esta tradición se olvidó de la dimensión ética que 
el deseo carga desde su origen, y de la necesidad de que éste sea plenamente comprendido y ajustado por la razón para que el hombre pueda realizar una vida buena.

Me propongo, pues, releer algunas de las tesis más importantes de Agustín y de Pascal sobre el deseo y alumbrarlas desde una perspectiva que conciba el deseo [appetitus] como el primer momento del itinerario del hombre hacia el Bien. En primer lugar intentaré describir la situación fundamental de la existencia del hombre que Agustín llamó inquietudo cordis y cómo esta inquietud cobra fuerza en la filosofía moderna gracias al pensamiento de Pascal. En segundo lugar, explicaré el modo como esta situación inicial de inquietud da lugar a la concreción de los proyectos vitales a través del mecanismo del deseo, y cómo este deseo puede llevar al hombre a puerto seguro o, bien, puede tergiversarse en el despliegue de las concupiscencias, con lo que el proyecto humano puede llegar al naufragio. Para concluir, explicaré cómo tanto para Agustín como para Pascal, si bien el deseo humano trae consigo -inscrito en su propia estructura- que el único objeto posible de su satisfacción es un Absoluto, este deseo solamente puede llegar a buen término si el hombre asume radicalmente su finitud e insuficiencia y permite que una gracia le reconstituya su condición.

\section{La inquietudo cordis en Agustín y Pascal}

No es nueva la idea de entender a Pascal como un lector de Agustín de Hipona². Ya desde los inicios de los Pensées, Pascal plantea la problemática de la condición de humana en clave agustiniana. Los primeros fragmentos se ocupan de describir esta difícil situación en la que la vida es un problema y las herramientas que tenemos para resolver el enigma suelen verse ennegrecidos por nuestros propios vicios. Miseria y grandeza humana están en constante fluctuación por una vanidad y vacuidad que nos azota, y por una razón que nos permite comprender sólo alguna parte de la verdad sobre nosotros mismos: “¿qué debo hacer? No veo más que obscuridades. ¿Creeré que no soy nada? ¿Creeré que yo soy Dios? Todas las cosas cambian y se suceden. Te equivocas, hay..."3 La pregunta sobre el deber y sobre el destino hacia el cuál hay que dirigir la vida es la base de toda la filosofía pascaliana, sobre todo en la medida que la vida se experimenta como el proyecto que depende de nuestra propia libertad. La alternativa se presenta como la alternativa entre creer ser la nada frente a Dios o creer ser Dios en tanto creerse siempre suficiente: o ser el

\footnotetext{
2 El mejor trabajo, hasta ahora publicado, a propósito de las relaciones y conexiones entre Agustín de Hipona y Blaise Pascal es el de P. Sellier (1979).

3 Pascal, Pensées, 2, 2. Para indicar el fragmento correspondiente de los Pensées coloco dos números. El primero corresponde a la edición de Michel Le Guern, el segundo, seguido de una coma, corresponde a la edición de Lafuma. Las traducciones son mías.
} 
vacío completo o ser el entero todo. El hombre oscila, para Pascal, siempre entre esos dos extremos.

La simpatía de Pascal por Agustín no es casual pues para éste la vida misma se presenta también como un enigma. El libro IV de las Confesiones es elocuentísimo en este punto. En él Agustín narra la experiencia a partir de la cual la vida entera y él mismo se convirtieron en un problema grandísimo:

¡Con qué dolor se oscureció mi corazón! Todo lo que miraba era muerte para mí. La patria era un suplicio, y la casa paterna un tormento insufrible, y todo lo que había compartido con él se me volvía sin él un cruelísimo suplicio. Mis ojos lo buscaban por todas partes y no aparecía. Y llegué a odiar todas las cosas, porque no lo tenían ni podían ellas decirme ya, como antes, cuando venía después de ausentarse: «he aquí que ya viene». Me convertí en una gran pregunta para mí mismo [factus eram ipse mihi magna quaestio] y preguntaba a mi alma por qué estaba triste, y me conturbaba, y no sabía qué responderme. Y si yo le decía: «Espera en Dios», ella no me hacía caso... y tenía razón; porque más real y mejor era aquel amigo queridísimo que había perdido que aquel fantasma en que se le ordenaba que esperase. Sólo el llanto me era dulce, y ocupaba el lugar de mi amigo en las delicias de mi corazón. ${ }^{4}$

La experiencia que Agustín aquí nos cuenta se dispara por la muerte de uno de sus mejores amigos, pero en realidad no hace más que poner en la carne de un ejemplo concreto la constatación que hace un hombre, cualquiera, de la finitud de su propia vida, del momento por el cual comprende que no da igual cómo viva y por el que comprende que la existencia humana está sujeta a una cantidad de veleidades y otras no tanto, pero sobre las cuales hay sin duda que decidir, decisión que ha de tomarse sobre la base de nuestra inconstancia, incapacidad y torpeza para poder realizar los ideales que podamos de alguna manera vislumbrar. "Condición del hombre. Inconstancia, aburrimiento, inquietud"5, dice Pascal. "Sentía un grandísimo tedio de vivir y al mismo tiempo tenía miedo de morir"6, dice Agustín. La contradicción entre los deseos es evidente: no se desea vivir para siempre tal como vivimos, pues esa tal vida produciría tedio y hastío, pero tampoco se desea la muerte, a la cual se le teme desde la hondura más profunda del alma. "Inconstancia. Las cosas tienen diversas cualidades y el alma diversas inclinaciones, porque nada de lo que se ofrece al alma es simple y el alma no se muestra simple en ningún caso. Por eso lloramos y reímos de una misma cosa."7. Deseamos el mundo, pero éste produce

\footnotetext{
4 Agustín de Hipona (2005) IV, 4, 9. Las traducciones de los textos de Agustín son reelaboraciones mías a partir de las versiones de la BAC. Para referenciar los pasajes utilizo el modo tradicional de citar su obra: en romanos indicio el número de libro y en arábigos el capítulo y, si es el caso, parágrafo. El año corresponde a la edición que he tenido en cuenta.

5 Pascal, Pensées, 22, 24.

6 Agustín de Hipona (2005) IV, 6, 11.

7 Pascal, Pensées, 50, 54.
} 
hartazgo e insatisfacción: inquietudo cordis. No está tan claro en dónde hemos de encontrar al Bien perfecto que satisfaga los más hondos anhelos de este corazón inquieto: vivimos en la vida de la disimilitud y la desemejanza. ${ }^{8}$

Es el horizonte temporal de la existencia humana lo que la sitúa en unas coordenadas difíciles de asir para nuestra pobre voluntad y capacidad de dominio. Al verse sometido al tiempo, al ver que su existencia no es estática y definitiva sino que, por el contrario, está en constante devenir, el hombre experimenta el oxímoron de la perenne contingencia de las cosas, tanto de los objetos del mundo como de los estados del ánimo que colorean y dan figura, forma y fondo a cada momento de la vida. El horizonte del tiempo es, pues, imprescindible para comprender esta inquietudo cordis agustiniana que luego Pascal expresará al hablar de la naturaleza humana: "la naturaleza del hombre no siempre va hacia adelante. Tiene sus idas y venidas. La fiebre tiene sus fríos y sus calores, y el frío muestra tanto la grandeza del ardor de la fiebre como la grandeza del calor mismo. Todas las creaciones de los hombres, de siglo en siglo, son siempre las mismas. La bondad y la malicia del mundo es, en general, la misma. Plerumque gratae princibus vices." 9 Somos siempre los mismos, pero con movimientos internos permanentes e insertos en la historia, y es esta historicidad -nuestro desvelamiento del ser en el tiempo- lo que produce en nosotros desasosiego: experimentamos todo presente siempre como el único, o como definitivo pero también como determinantemente provisional. 10

La vida es permanente cambio, nada en ella está quieto, ella es inquietud. Por eso lo que anhela el corazón es justamente la paz, el cese de los movimientos, la definitividad y el fin del cambio, la estabilidad que le permita afirmarse a sí y afirmar sus más grandes amores de manera definitiva. De este incesante riesgo de pérdida surge nuestro miedo, pues cuando no tenemos lo que deseamos, tememos no conseguirlo, y una vez conseguido, tememos perderlo. Por eso el horizonte temporal define la inconstancia atemorizante de nuestra vida: "la existencia del hombre está desgarrada por tensiones interiores y al mismo tiempo oscilando entre los puntos de referencia objetivos del universo exterior. La situación adquiere un carácter crítico especial en la relación, que preocupó tanto a Pascal, entre el infinito limitado y el infinito ilimitado"11. Esta idea de infinito -limitado por un lado e ilimitado por otro- es la que tira al hombre en sus deseos y lo insta a perseguir esta beata vita que de alguna manera proyecta pero que no puede alcanzar definitivamente debido al horizonte de su temporalidad. Muchas cosas tiran del hombre, pero solamente la idea de infinito tira de él con verdad porque todo lo que es finito perece y, por lo tanto, muda y cambia. Si aspiramos a la quietud, entonces hemos de aspirar tam-

\footnotetext{
8 Cfr. Agustín de Hipona (2005) VII, 10, 16.

9 Pascal, Pensées, 25, 27.

10 Cfr. A. Villar (2010) pp. 265-278.

11 Guardini (1955) p. 68.
} 
bién, de algún modo, a que lo infinito penetre o permee por entero la finitud permanente que rodea la existencia.

La temporalidad, por eso, cobra una importancia decisiva para comprender el drama de la existencia según Agustín y Pascal. Como lo definió Agustín, el tiempo es la distentio animi: no otra cosa es el tiempo que el movimiento del alma para retener lo pasado o para prevenir lo futuro: "en ti, alma mía, mido los tiempos. No me molestes, que así es; ni te molestes a ti con los movimientos de tus afectos. En ti -repito- mido los tiempos. Es con el afecto que te producen las cosas que pasan -y que, aún cuando hayan pasado, permanece- con lo que yo mido el presente, no con esas cosas que pasaron para producirlo: cuando mido el afecto, mido los tiempos. Luego, o éste es el tiempo, o yo no mido el tiempo"12. Agustín sitúa el tiempo en la dimensión propiamente subjetiva de la vida y no como un objeto: el tiempo es el devenir del alma, es su expansión hacia los recuerdos del pasado cuando hace por retenerlos y volverlos a traer al único presente, así como la expectación de un futuro incierto, incertidumbre que hace indeterminado todo presente. La vida es, pues, posibilidad; posibilidad de obtener lo que se desea o posibilidad de perder lo que ya se tiene. Por eso la inquietud del corazón solamente cesará cuando el alma repose en un Dios que sea estabilidad máxima, en el único bien permanente que no se pueda perder aunque quiera perdérsele. $Y$ es en eso precisamente en donde está el drama: como de Dios no tenemos experiencia sensible, en su devenir mundano la existencia humana no es nunca definitividad sino un permanente estado intermedio entre lo que ya se tiene o ya se conoce y lo que aún ni siquiera se prevé que pueda llegar a tenerse; la vida es grandeza y miseria, como decía Pascal: "no nos tenemos nunca en el tiempo presente" 13 y, también: "grandeza y miseria. La miseria se concluye de la grandeza y la grandeza de la miseria [...] En una palabra, el hombre conoce que es miserable. Él es miserable porque es, pero es grande porque sabe que es miserable." 14

Estamos tejidos desde la contradicción, pensarán tanto Agustín como Pascal, por eso a pesar de tener en esta vida ciertas verdades y algunas experiencias de definitividad o de gloria, inmediatamente las despreciamos por las razones, quizás, más vanas que puedan pensarse. Por eso la vida se teje bajo la tesitura de un cierto hartazgo o aburrimiento: "la elocuencia continua del aburrimiento. Los príncipes y reyes juegan alguna vez. No están siempre sobre sus tronos. Se aburren. La grandeza tiene la necesidad de ser suprimida para poder ser sentida. La continuidad asquea en todo. El frío es agradable porque hay calor. La naturaleza actúa por el progreso. Itus et reditus, ella pasa y vuelve, luego va más lejos, luego dos veces menos, luego más que nunca, etc. Así se hace el flujo de la mar, el sol parece funcionar así" 15.

\footnotetext{
12 Agustín de Hipona (2005) XI, 27, 36.

13 Pascal, Pensées, 43, 47.

14 Pascal, Pensées, 113, 122.

15 Pascal, Pensées, 646, 771.
} 
La inquietudo cordis, en este sentido, no podría entenderse más literalmente: es la situación de permanente mutabilidad, de constante falta de quietud en los afectos ${ }^{16}$, de los movimientos permanentes del alma y que perturban la estabilidad, o que hacen imposible el sosiego definitivo que anhela el corazón. Así lo expresa Agustín: "no se trata de la quietud de la desidia, sino del ocio del pensamiento que se desembaraza de lo temporal y local. Porque estos fantasmas hinchados y volubles no nos permiten llegar a la constancia de la unidad" 17 .

Esta inestabilidad se hace patente aún más bajo la conciencia de la experiencia de la muerte como un horizonte ineluctable hacia el que el ser humano ha de dirigirse sin posibilidad de cambiar nada a ese respecto, y ante el cual se siente un vértigo como se siente terror ante un abismo de honduras insondables 18 : "entre nosotros y el infierno o el cielo, no hay más que la vida entre dos, que es la cosa más frágil del mundo"19 Así, la experiencia de la fragilidad, de la contingencia, de la permanente insatisfacción y veleidad es la experiencia que fundamenta toda otra búsqueda de sentido y toda búsqueda de significados en el itinerario vital de cualquier hombre 20 .

En Pascal, esto desata precisamente la búsqueda filosófica y la necesidad de admitir que no basta con el conocimiento científico del mundo. Es necesario fomentar, por una parte, el espíritu de fineza para poder comenzar a comprender algunas de las verdades más importantes: "la ciencia de las cosas exteriores no nos consolará de la ignorancia de la moral en tiempos de aflicción, pero la ciencia moral me consolará siempre de la ignorancia de las ciencias exteriores"21, pero, por otra parte, también esta inquietud para Pascal representa el inicio del itinerario del deseo, que puede desenvolverse afrontando su propia finitud o negando la realidad en la diversión, el divertimento, en el darle la espaldas a la verdad.

Para Agustín, por otro lado, el miedo a la muerte suele experimentarse como la caída o como la experiencia del vértigo frente a un abismo profundísimo, como si fuera la experiencia del lugar, o de la estabilidad en el espacio y sobre la tierra, lo que se pone precisamente en cuestión cuando la finitud se hace tan patente que la muerte queda expuesta a los ojos del sujeto: "¿qué es lo que quiero decirte, Señor, sino que no sé de dónde he venido aquí, a esta vida mortal o muerte vital?"22, pre-

16 Recordemos la idea de San Ignacio de Loyola (en un sentido otro agustiniano en los albores de la Modernidad): “...quitar de sí todas las affecciones desordenadas...”, (1982, [1]).

17 Agustín de Hipona (2011) XXXV, 65.

18 Cfr. P. Sellier, (1979), 28.

19 Pascal, Pensées, 142, 152.

20 Esta afirmación podría tener importantes consecuencias teológicas, sobre todo respecto del modo como se concibe las relaciones entre naturaleza y gracia. Una nota breve pero suficiente sobre la discusión entre Pascal y el jansenismo sobre el tema de la gracia eficaz, remito a Gouhier (1966) pp.316329 y (1978) pp. 123-146.

21 Pascal, Pensées, 21, 23.

22 Agustín de Hipona (2005) I, 6, 7. 
gunta Agustín desde la hondura de su congoja... "una tristeza insoportable"23, dirá Pascal.

No le quedan al hombre más que dos opciones: o reconocer su propia finitud y abandonarse a una verdad mucho más grande que él mismo, o elegirse a sí mismo y vivir bajo el divertimento de libido ${ }^{24}$. Lo importante es que esta situación de "desfondamiento" 25 o de falta de una solidez ontológica es lo que desatará la vida como proyecto, lo que hará que el deseo funja como el primer detonante de la búsqueda de un sentido26. "¿Porqué mi conocimiento es limitado? ¿Mi tamaño? ¿Porqué mi duración es de cien años y no de mil? ¿Qué razón ha tenido la naturaleza para concedérmela así y de elegir este número y no otro de la infinitud de los cuales no hay más razón de elegir uno que otro, pues no hay nada que en uno atraiga más que en otro?"27. El sentido de la existencia no es evidente, por lo que la inquietud es una nota estructural del hombre. Somos inestabilidad y medianía. Pero el deseo es, sin embargo, precisamente lo que quiere remediar esa inestabilidad, es el movimiento que surge hacia la alteridad. Siendo él mismo movimiento, el deseo busca la quietud.

\section{El deseo y su resolución: caritas et libido}

"Conocemos la verdad no solamente por la razón, sino también por el corazón," 28 dice Pascal. De hecho, la categoría del cour -o del cor, para los latinos-, es una de las estructuras antropológicas fundamentales para comprender la filosofía agustiniana y también el pensamiento de Pascal. De resonancia eminentemente bíblica, el corazón agustiniano -que es también el corazón de los Salmos y de los profetas 29 -, funciona como el centro total de la persona, como el lugar en el que convergen todas las facultades y potencialidades propias del hombre: inteligencia, memoria y voluntad - de acuerdo con la antropología trinitaria-, pero también el

\footnotetext{
23 Pascal, Pensées, 33, 36.

24 Cfr. Agustín de Hipona (2007), XIV, 6-10.

25 Cfr. Gabriel Amengual, (2012).

26 Sobre las relaciones entre esta experiencia de desasosiego, la idea del vacío y la metodología de Pascal, cfr. J.P. Fanton d'Andon (1978).

27 Pascal, Pensées, 183, 194-197.

28 Pascal, Pensées, 101, 110.

29 En hebreo, lêb o lêbâb; según los setenta, kardia; según la Vulgata, cor. El corazón es el centro de la vida en sentido biológico, pero también el centro de la vida espiritual e intelectual, así como el lugar en el que se aloja la memoria. Por último, entre otras cosas y según nos interesa afirmar ahora, el corazón es también el centro del cual surgen los deseos y las inclinaciones, tanto los buenos como los malos: "todos los hombres, impulsados por su corazón, vinieron a traer la ofrenda reservada a Yahvé" Ex 35, 21; "yo les daré un solo corazón y pondré en ellos un espíritu nuevo: quitaré de su carne el corazón de piedra y les daré un corazón de carne" Ez 11, 19-20.
} 
cuerpo y el alma, de acuerdo con la estructura de la propia persona. Asimismo, en Pascal, el corazón es la realidad misma del hombre: "porque el conocimiento de los primeros principios, como que hay espacio, tiempo, movimiento, números, y tan fuerte como cualquiera de nuestros razonamientos, es sobre estos conocimientos del corazón y del instinto que la razón se apoya y en donde funda todo su discurso"30. La razón se sitúa, al menos desde esta perspectiva, en una relación de dependencia respecto del corazón, pues es él una realidad anterior y más fundamental al ejercicio de raciocinio, tanto desde su dimensión de espíritu de geometría como desde su dimensión de espíritu de fineza. Es el corazón el primer lugar antropológico al cual se revela el bien y la verdad. 31

Conocemos la verdad por el corazón, dice Pascal. Pero este corazón es, en la realidad humana, un corazón eminentemente inquieto, pues inquietum est cor nostrum. La inquietud misma tiene un papel fundamental en el conocimiento de la verdad: la inquietud, de algún modo comienza a revelárnosla o a ofrecérnosla. Si bien quizás como aquella realidad en la cuál no estamos todavía, hay que decir que esa inquietud del corazón nos puede decir mucho más sobre el deseo humano, o sobre nuestro propio destino que lo que a primera vista podría parecer. ${ }^{32}$

El hombre es, sin Dios, miserable, y es la ausencia de Dios -o, para ser más precisos, el deseo dirigido hacia lo que no es Dios- lo que provoca la inquietudo cordis. De modo que el primer dato de aquello hacia donde nuestro corazón, en la forma de sus deseos, apunta está ya presente en la inquietud, en el desasosiego, en la constatación de la no definitividad del mundo. El corazón es la primera verdad sobre el hombre, no ya solamente porque nos revela los primeros principios sino también porque su inquietud es el primer dato a tomar en cuenta en la constitución de nuestro deseo. 33

Para resolver el gran enigma del hombre, es decir, para que cada uno pueda resolver el gran lío que constituye su propia vida, ha de atender a la inquietud de su corazón como primer dato fundamental para poder constituir su deseo, y así dirigir su vida y determinar su propio proyecto. De acuerdo con Agustín este deseo (appetitus) puede desplegarse de dos formas: como caritas, si es que se dirige al Bien, o como cupiditas -o libido-, si es que se dirige hacia sí mismo.

Al calificar a toda la realidad como buena, la ontología agustiniana no permite que la voluntad tenga un movimiento defectible hacia una realidad inferior a ella. Por eso el pecado, o libido, se da no cuando la voluntad se dirige a un bien inferior,

\footnotetext{
30 Pascal, Pensées, 101, 110.

31 Un texto interesante al respecto, del propio Pascal, es el Discurso acerca de las pasiones del amor (2010). Ha sido Henri Gouhier uno de quienes han hecho énfasis en esta capacidad del corazón para conocer y su estructura respecto de toda la antropología pascaliana. Cfr. Gouhier (1986), pp. 54-70.

32 Cfr. P. Sellier (1999), p. 207.

33 Sobre las relaciones entre el cor agustiniano y el cœur de Pascal, cfr. P. Sellier (1979), pp. 117-139.
} 
sino cuando se dirige hacia sí misma, considerándose como autosuficiente para satisfacer sus deseos y negando con ello la absoluta preeminencia de Dios, el summum bonum sobre toda la creación 34 : "así es como entendí, por propia experiencia, aquello que había leído sobre cómo la carne apetece contra el espíritu y el espíritu contra la carne, estando yo realmente en ambos, aunque estaba más yo en aquello que aprobaba en mí que en aquello que en mí desaprobaba; porque en lo que la carne apetecía contra el espíritu había más de no yo, puesto que en su mayor parte más padecía contra mi voluntad que obraba queriendo. Con todo, de mí mismo provenía la costumbre [consuetudo] que prevalecía contra mí, porque queriendo había llegado a donde no quería"35.

Este texto, dialécticamente complicado, revela varias dimensiones del yo y de la voluntad, varios niveles de desear, de actuar y de querer. Distingamos, por lo pronto, dos instancias o modos de la voluntad: en primer lugar, hay una primera voluntad que se dirige siempre e indefectiblemente al summum bonum, es un movimiento irresistible del yo. En segundo lugar, hay otra voluntas que asume a esta primera y la afirma o la niega libremente ${ }^{36}$. En caso de que la afirme, la voluntad se unifica y se dirige al bien, transformándose así en caritas. Si la niega, entonces podemos afirmar que se ha elegido a sí misma, clausurándose en un movimiento inmanente y transformándose con ello en libido: “¿a quién hablaré yo y cómo le hablaré del peso de la concupiscencia, que nos arrastra hacia el abrupto abismo, y de la elevación de la caridad por tu Espíritu, que era sobrellevado sobre las aguas?"37. Caridad y concupiscencia, amor y libido, son los dos tipos de deseos, las dos voluntades que surgen del hombre según el objeto hacia el cuál se dirijan ${ }^{38}$ : si se dirige a Dios, se transforma en amor y en caridad, si se dirige hacia sí misma, se transforma en concupiscencia. ${ }^{39}$ Por que el alma no puede dirigirse, ni queriendo, a bienes inferiores a sí misma. El ordo es a tal punto un orden ontológico que no puede romperse: cuando en lugar de traspasarse a sí misma y dirigirse a Dios, se conforma consigo misma para satisfacer sus anhelos, el alma pervierte su movi-

\footnotetext{
34 Cfr. Agustín de Hipona (2009) III.

35 Agustín de Hipona (2005) VIII, 5, 11.

36 Cfr. Agustín de Hipona (2007), XIV, 6.

37 Agustín de Hipona (2005) XIII, 7, 8.

38 Cfr. H. Arendt (2010), pp.25-26.

39 Acerca de la traducción de los términos libido y cupiditas, optamos por libido. El mismo Agustín, en el libro XIV de De Civitate Dei, reconoce la ambigüedad de la palabra cupiditas pues, si bien en su sentido lato significa cualquier deseo, suele utilizarse para los deseos perversos. Libido, en cambio, aunque en su sentido moderno suele restringirse al impulso sexual, sobre todo al uso que el psicoanálisis ha dado a esa palabra, para Agustín y los latinos se refiere a cualquier deseo perverso de cualquier tipo de especie y sea cual fuere su objeto. Libido tiene entonces un sentido más restringido que cupidtias, por lo que optamos por verterlo al español por su equivalente homofónico, advirtiendo que el uso que le damos aquí no es el restringido de deseo sexual.
} 
miento: "que este mi corazón te diga qué era lo que allí buscaba para ser malo en vano y que mi maldad no tuviese más causa que la maldad. Fea era, y yo la amé; amé perecer, amé mi defecto, y no aquello por lo que faltaba, sino mi mismo defecto. Torpe alma mía que, saltando fuera de tu base, ibas al exterminio, no buscando algo en el deseo, sino el deseo mismo" 40 . En los comentarios a los Salmos señala ya explícitamente los nombres de los dos tipos de deseos: "con razón se entiende por base del alma el amor [amor], que siendo maligno se llama concupiscencia o libido [cupiditas aut libido], pero cuando es bueno, dilección o caridad [dilectio vel charitas]"41.

En este sentido el appetitus, el deseo (que se identifica con el sentido más lato de la palabra amor, que en Agustín se refiere a prácticamente cualquier deseo) es el primer móvil de realización de la voluntad libre de la persona, y lo que la impulsa a salir de sí y a buscar aquella realidad que pueda realizarla y plenificarla. El problema es que, como lo ha dicho Aristóteles, se puede ser malo de muchos modos y bueno de una sola manera. Por ello, caritas o amor, que es el appetitus bien dirigido, sólo ha de dirigirse a un objeto: al summum bonum, por lo que solamente hay una clase de amor, aunque las virtudes sean muchas y las bienaventuranzas también. En cambio, la voluntad puede pervertirse de muchas y diversas maneras, por lo que tanto Agustín como Pascal dedicaron importantes palabras a la explicitación de las tres concupiscencias ya presentes incluso desde el Nuevo Testamento.

\section{Las tres concupiscencias}

"Concupiscencia de la carne, concupiscencia de los ojos o ambición del siglo" (1Jn 2, 16), dice el apóstol Juan. Y, en efecto, Agustín dedica la última parte del libro X de las Confesiones a describir estos tres modos de concupiscencia. Estas tres "tentaciones" funcionan como la permanente voz que va constituyendo actividad: ellas invitan al hombre a hacer ciertas cosas y éste ha de tomar posición al respecto y actuar en consecuencia. A este desenvolvimiento de la existencia se le ha conocido como cura vitae, el cuidado de la vida. El hombre se preocupa por el objeto al que dirige sus deseos, teniendo presente el profundo deseo de beata vita e intentando resolverlo con una diversidad grande de bienes.

La concupiscencia de la carne, en primer lugar, es el gozo en el placer mundano de los sentidos, de cualquier sensación que no represente más que deleite carnal. Sin embargo hay que aclarar que lo problemático no está tanto en la posible perversidad de los objetos de tales placeres, a saber, el mundo (tal perversidad es inexistente: para Agustín todo el mundo es bueno), sino que lo problemático surge en el

\footnotetext{
40 Agustín de Hipona (2005) II, 4, 9.
}

41 Agustín de Hipona (1964) 9, 15. 
modo como libido los desea: "no temo yo la inmundicia de la comida, sino la inmundicia de la concupiscencia [cupiditatis]"42, dice Agustín: ni la comida ni la maravilla de los colores ni la belleza de la música o el perfume de las flores son realidades malas o indeseables. Lo malo está en el gozarse libidinosamente en su carnalidad sin tomar en cuenta que hay una verdad y un bien superior a ellas que las hace ser gozosas 43 . La luz, por ejemplo, del día en el campo, los colores de los animales y de las flores son motivo, incluso, de alabanza de Dios, el único bien Absoluto: "esta luz corporal de que antes hablaba, con su atractiva y peligrosa dulzura, sazona la vida del siglo a sus ciegos amantes; mas cuando aprenden a alabarte por ella, ¡oh, Dios creador de cuanto existe!, la convierten en un canto tuyo, sin ser encantados y arrobados por las ensoñaciones que provoca. Así quiero ser yo"44.

Sobre la segunda concupiscencia, aún más grave y más peligrosa, la "concupiscencia de los ojos", dice Agustín que se llama así no porque consista ella en el deleite de la vista, sino porque los ojos son la metáfora del conocimiento. "Hay una vana y curiosa concupiscencia, paliada con el nombre de conocimiento y ciencia, que radica en el alma a través de los mismos sentidos del cuerpo, y que consiste no en deleitarse en la carne, sino en experimentar cosas por la carne. Esta curiosidad, como radica en el deseo de conocer y los ojos ocupan el primer puesto entre los sentidos ordenados al conocimiento, es llamada en el lenguaje divino concupiscencia de los ojos" 45 . Es la curiosidad, es la distracción en el conocimiento de cosas vanas por la mera dilección estética que provoca conocer el mundo y saber cuáles son sus más íntimos secretos. Éste es el segundo tipo de tentación. No hace falta demasiado para saber que Pascal también vio esto y lo asoció con la vanidad, con esa tendencia del hombre por ocuparse de lo superfluo, de conocer el mundo aunque se sepa de antemano que es contingente y que poco importa. El conocimiento aquí no se toma como un medio sino que se vuelve un divertimento en sí mismo que distrae al hombre de su verdadera condición de fragilidad: "quien no ve la vanidad del mundo, es vano él mismo"46, dice Pascal. Y en otro fragmento: "los hombres se ocupan en perseguir una pelota o una liebre; hasta es el placer de los mismos reyes" 47 , "el hombre común cree sinceramente que la caza es un gran placer de reyes". 48

\footnotetext{
42 Agustín de Hipona (2005) X, 31, 47.

43 Así como no es nada del mundo lo que torna malo al hombre, tampoco son las pasiones que pueda sentir. Como veremos más adelante, el problema está en la voluntad misma, en el alma perversa que, deseándose a sí misma, se hace mala. En esto radica una de las aportaciones principales de Agustín respecto del estoicismo y el neoplatonismo: mientras que ambas filosofías condenaban a las pasiones, Agustín es incapaz de concebir una felicidad sin ellas, así que "no importa si sufres passiones o no: lo que importa es el modo como tu voluntad las maneja.” J. J. O’Donnell (1992), v.III, p. 31.

44 Agustín de Hipona (2005) X, 34, 52.

45 Agustín de Hipona (2005) X, 35, 54.

46 Pascal, Pensées, 33, 36.

47 Pascal, Pensées, 36, 39.

48 Pascal, Pensées, 126, 136. Agustín utiliza exactamente el mismo ejemplo en Confesiones (2005) X, 36, 59 para hablar de la perdición del hombre en la banalidades del mundo: "cuando hay una en el circo,
} 
Por último, en fin, está el tercer género de concupiscencia, que es el más tremendo y arrollador de todos. Es el más terrible y causa de todos los demás: "¿por ventura puede dejarme durante toda esta vida este tercer género de tentación, que consiste en querer ser temido y amado de los hombres no por otra cosa sino por conseguir de ello un gozo que no es gozo? ¡Mísera vida es y fea jactancia!”49. La tercera concupiscencia busca el temor de los hombres, busca el respeto y el poder. Es la hybris que, deseando desordenadamente, está dispuesta a ordenar el mundo para sus propios fines. "La tiranía consiste en el deseo de dominación universal y fuera de todo orden" 50 , dice Pascal. Esta concupiscencia, pues, surge cuando al contemplarse a sí mismo el hombre y horrorizarse de su incapacidad y de su fragilidad, se inflama y se hincha de soberbia para parecer más de lo que es. No otra cosa es, pues, esta tercera concupiscencia, que el orgullo y la soberbia, la última y la primera de todas las tentaciones: "y seréis como dioses" $(\mathrm{Gn} 3,5)$.

Tres tentaciones, tres concupiscencias forman el catálogo de caídas y recaídas humanas: "placer, ambición, espectáculo"51, las llama Agustín, o "liviandad, soberbia y curiosidad" 52 , invirtiendo aquí el orden. Pero éstas, sin embargo, no llegan por sí solas. Si bien nuestra naturaleza es miserable, pequeña y necesitada, contingente y defectuosa por el pecado, no podemos quitar culpa al hombre, pues todo vicio surge de la necesidad que, a su vez, nace de la costumbre. Y la costumbre no es banal en la filosofía pascaliana. La concupiscencia, ni para Agustín ni para Pascal son añadidos eventuales a nuestra condición sino que pareciera que se han convertido en la hermana malvada que acompaña siempre al hombre, al grado que Pascal llega a llamarle "segunda naturaleza": "nuestra concupiscencia se ha vuelto natural y se ha hecho nuestra segunda naturaleza. Así, hay dos naturalezas en nosotros: una buena, otra malvada. ¿Dónde está Dios? En donde no estás tú, y el reino de Dios está en ti" 53 . Parece, pues, que esta naturaleza contradictoria nos lleva de un lado a otro a lo largo de la historia de la vida. Por un lado, podemos ser maravillosamente grandiosos, cuando conocemos, cuando reflexionamos, cuando heroicamente nos abandonamos al Dios de la fe y aceptamos que somos limitados. Pero si somos capaces de ese movimiento de alabanza y de confesión, somos también capaces de olvidarnos de él y convertirnos y verternos al mundo, generando hábitos y costumbres que van tejiendo un caparazón y una segunda naturaleza en nosotros. En este punto la vanidad tiene un papel importantísimo, pues nuestra ceguera o nuestro cul-

\footnotetext{
ya no contemplo la carrera del perro tras la liebre; pero en el campo, cuando por casualidad paso por él, todavía atrae mi atención hacia sí aquella caza y me distrae tal vez hasta de algún gran pensamiento y me hace salir del camino, no con el jumento que me lleva, sino con la inclinación del corazón."

49 Pascal, Pensées, 54, 58.

50 Pascal, Pensées, 54, 58.

51 Agustín de Hipona (2011) XXXVIII, 69.

52 Agustín de Hipona (2011) XXXVIII, 70.

53 Pascal, Pensées 523, 616.
} 
pable ocultamiento de las más primarias necesidades nos conducen a crearnos máscaras que, por una parte, no nos muestren al mundo como realmente somos y, por otra, no nos muestren a nosotros el mundo como realmente es: "la vanidad preside nuestras costumbres y por las costumbres se refuerza. Nos gobierna por completo y es capaz de establecer una segunda naturaleza en el ser humano"54. Así, por la fuerza de la costumbre nos hemos convertido en una naturaleza de concupiscencia, libido nos ha conducido a una especie de monstruificación en la que ya no solamente somos hombres, sino hombres dobles. Agustín mismo lo describe de la siguiente manera:

porque de la voluntad perversa [ex voluntate perversa] nace libido [libido], y de una libido [libido] obedecida procede la costumbre [consuetudo], y de la costumbre no contradicha proviene la necesidad [necessitas]; y con estos a modo de anillos entrelazados entre sí -por lo que antes llamé cadena- me tenía aherrojado en dura esclavitud. Porque la nueva voluntad que había empezado a nacer en mí de servirte gratuitamente y gozar de ti -ioh Dios mío!, único gozo cierto-, todavía no era capaz de vencer a la primera, que con los años se había hecho fuerte. De este modo las dos voluntades mías, la vieja y la nueva, la carnal y la espiritual, luchaban entre sí y peleando destrozaban mi alma. 55

Es el yo quien se pierde a sí mismo, el propio sujeto abandonado a sí lo que le coloca en el vértice central del triángulo de las concupiscencias. El hombre puede así ser grandísimo, pero solamente si confiesa su miseria y deja que su deseo sea reconfigurado por el único bien capaz de restituirlo en su fuerza para que así se dirija a lo que lo hará realmente grande. Por eso es importantísima la relación entre naturaleza y costumbre, pues parece que la naturaleza humana se teje de costumbres y de hábitos que, con la repetición, van otorgando una identidad y van surcando el camino que lleva de la inquietudo cordis a la pax de la vida bienaventurada: "cuando vemos que un efecto acontece siempre igual -dice Pascal-, concluimos una necesidad natural, como que mañana será otro día, etc. Pero frecuentemente la naturaleza nos desmiente y no se sujeta a sus propias reglas. El espíritu cree naturalmente, y la voluntad ama naturalmente, de suerte que a falta de objetos verdaderos, se agarra de los falsos" 56 , de manera que fracasemos o triunfemos en la consecución de nuestros deseos, vamos tejiendo nuestra identidad de aquello que obtenemos según nuestras voluntades van ejerciendo su acción en el mundo.

Tanto en Agustín como en Pascal, las dos voluntades están permanentemente en lucha: una tirando al mundo y la otra, inscrita en el deseo (appetitus) más íntimo, se dirige indefectiblemente a Dios. El deseo, así concebido, no solamente es llama-

54 Villar (2012) LXXXIII.

55 Agustín de Hipona (2005) VIII, 5, 10.

56 Pascal, Pensées, 559, 660. Sobre las relaciones entre naturaleza y costumbre en Pascal, ver el trabajo de G. Ferreyrolles (1995) pp. 39-64. 
da de Dios sino también respuesta a ese primer llamado que me interpela ${ }^{57}$. Por eso es en él en donde surge la batalla entre mi propio deseo y el deseo del Bien: ambos como míos pero uno más mío que otro: uno más íntimo a mí que yo mismo. Por esa razón no es una lucha como la imaginaba el maniqueismo, sino que hay una prevalencia -al menos formal, por su telos- de la voluntad o del deseo de beata vita, pues aún cuando se busquen los más ínfimos males y las más bajas de las inmundicias, aunque parezca que el hombre se está buscando únicamente a sí mismo, emprende esa búsqueda porque piensa que es la mejor, porque ve en ella el mejor estado de cosas y la mejor realización de su vida para conseguir así, también del mejor modo, la satisfacción y la paz de su corazón inquieto. "Con todo, de mí mismo provenía la costumbre que prevalecía contra mí, porque queriendo había llegado a donde no quería" 58 , dice Agustín, y si había llegado, queriendo, a donde no quería, es porque esta dualidad de las voluntades: la que quiere y la querida (como más tarde Blondel afirmará59), mantiene una tensión según la cual una de ellas se dirige siempre al bien, al summum bonum que está codificado en el cœur inquieto del salmista.

\section{Conclusión}

Hay, tanto en la filosofia agustiniana como en los fragmentos de Pascal una concepción contradictoria del hombre. Parece que, estructuralmente, vivimos en la tensión que surge del anhelo profundo de un Absoluto y el amor a las carnalidades del mundo. No obstante, esta disyuntiva, esta alternativa y estiramiento del alma solamente surge una vez que el hombre ha atravesado por el arduo camino de la insatisfacción y el desasosiego. Ni los maniqueos de Agustín ni los libertinos de Pascal han visto con plena patencia el drama que a ambos filósofos preocupa. Pero esta especie de ceguera forma ya parte de esta perenne imperfección humana, de esta naturaleza doblada y redoblada que no encuentra su proporción: "porque, en fin, ¿qué es un hombre en la naturaleza? Una nada frente al infinito, un todo frente a la nada, un medio entre nada y todo, infinitamente distante de comprender los extremos. El fin de las cosas y sus principios están para él invenciblemente escondidos en un secreto impenetrable" 60 .

Sin embargo, esta contradicción y este secreto pueden comenzar a ser resueltos en su paradoja por la claridad con la que el deseo quiere afirmar el absoluto. Pero

\footnotetext{
57 Sobre la llamada y la respuesta en San Agustín no solamente puede verse el bellísimo libro de Jean Louis Chrétien (1992), que es una elaboración fenomenológica y original sobre subjetividad y lenguaje, sino también el trabajo, elaborado específicamente desde una perspectiva pascaliana, de Louis Marin (1997) pp. 343-365.

58 Agustín de Hipona (2005) VII, 5, 11.

59 Cfr. M. Blondel (1996) pp. 137-179.

60 Pascal, Pensées, 185, 199.
} 
ese deseo se vuelve hacia sí mismo, haciendo que se odie el hombre, amándose a sí, pudiendo ser su natural inclinación, a saber, aquélla que se dirige al Absoluto, el primer vehículo para el rescate de la vida en libido. A este respecto, no puedo dejar de citar el maravilloso fragmento de los Pensées:

Después de haber mostrado la bajeza y la grandeza del hombre, estímese ahora el hombre en su justo precio. Que se ame, porque hay en él una naturaleza capaz del bien; pero que no por eso ame las bajezas que hay en él. Que se desprecie, porque esa capacidad está vacía; pero que no desprecie por eso esa capacidad natural. Que se odie, que se ame: hay en él una capacidad natural. Que se odie, que se ame: hay en él la capacidad de conocer la verdad y de ser feliz; pero no tiene ninguna verdad que sea constante o satisfactoria. Quisiera, por tanto, llevar al hombre a desear encontrarla, para que esté preparado y despojado de las pasiones, para seguirla a donde la encontrara, sabiendo cómo su conocimiento se obscurece por las pasiones; yo quisiera que él odiara en sí mismo la concupiscencia que lo determina, para que ésta no lo enceguezca al llevar a cabo su elección, y no lo detenga después de haber elegido61.

Las pasiones oscurecen el deseo humano de verdad, deseo natural, por el cual el hombre podría amarse adecuadamente, es decir, considerándose pequeño. Pero se ama tanto a sí mismo, y se considera tan grande y tan señor, que termina por odiarse al tergiversar esas pasiones y deseos en pasiones oscuras de concupiscencia. Con todo, tanto Agustín como Pascal quieren llevar al hombre "a desear", en el sentido fuerte, porque, entre otras cosas: "de toda su naturaleza, dos cosas instruyen al hombre: el instinto y la experiencia"62, de modo que ese instinct de Pascal, o el appetitus de Agustín tienen en su seno la llave de apertura para la gracia63.

En cualquier caso, tanto para el filósofo de Hipona como para su discípulo moderno, el hombre es una pequeña porción de la creación de un Dios que lo corteja y lo busca, lo llama y lo persigue, que a pesar de los dolores y desgracias nunca le abandona, y al que se puede acceder no solamente por un salto ciego de la fe sino también por el asentimiento de la razón humana, tanto en su dimensión rigurosamente matemática como en su dimensión cordial.

El drama de la existencia no se resuelve, tampoco, solamente en la disciplina del monje que se recluye en su monasterio de la perversidad del mundo sino que para ambos filósofos el deseo humano puede desenvolverse en el mundo, que en sí mismo es bueno, si lo considera como un bien a ser utilizado y disfrutado simplemente como un medio, como un punto de encuentro entre lo finito y lo infinito.

\footnotetext{
61 Pascal, Pensées, 110, 119.

62 Pascal, Pensées, 119, 128.

63 Cfr. É. Morot-Sir (1996).
} 


\section{Referencias bibliográficas}

Agustín de Hipona (1964): Enarraciones sobre los Salmos (1º), Obras Completas XIX. Madrid, Biblioteca de Autores Cristianos. Traducción de Balbino Martín Pérez O.S.A

Agustín de Hipona (2005): Confesiones, Obras Completas II. Madrid, Biblioteca de Autores Cristianos. Traducción de Ángel Custodio Vega O.S.A.

Agustín de Hipona (2007): La ciudad de Dios $\left(2^{\circ}\right)$, Obras Completas XIV, Madrid, Biblioteca de Autores Cristianos. Traducción de Santos Santamarta del Río y Miguel Fuentes Lanero

Agustín de Hipona (2009): De la naturaleza del bien, Obras Completas III. Madrid, Biblioteca de Autores Cristianos. Traducción de Mateo Lanseros O.S.A.

Agustín de Hipona (2011): De la verdadera religión, Obras Completas IV. Madrid, Biblioteca de Autores Cristianos. Traducción de Victorino Capánaga.

Amengual, G. (2012): Deseo, memoria y experiencia, Salamanca, Ediciones Sígueme.

Arendt, H. (2010): El concepto de amor en San Agustín, Madrid, Ediciones Encuentro, 2010. Traducción de Agustín Serrano de Haro.

Blondel, M. (1996): La acción. Ensayo de una crítica de la vida y de una ciencia de la práctica, Madrid, Biblioteca de Autores Cristianos. Traducción de Juan María Isasi y César Izquierdo.

Chrétien, J. L. (1992). L’Appelle et la réponse, Paris, Lés Éditions de Minuit.

FANTON D'ANDON, J.P. (1978): L'horreur du vide. Expérience et raison dans la Physique pascalienne, Paris, Éditions du centre national de la recherche scientifique.

FerReyrolles, G. (1995): Les Reines du monde. L'imagination et la coutume chez Pascal, Paris, Honoré Champion Éditeur.

Gounier, H. (1966): Blaise Pascal. Commentaires, Paris: Librairie Philosophique J. Vrin.

GouniER, H. (1978): Cartésianisme et augustinisme au XVIIe siècle, Paris, Librairie Philosophique J. Vrin.

Gounier, H. (1986): Blaise Pascal. Conversión et apologéthique, Paris, Librairie Philosophique J. Vrin.

Gómez Robledo, A. (1992): Estudios pascalianos, México, Fondo de Cultura Económica.

GuARDini, R. (1955): Pascal o el drama de la conciencia cristiana, Buenos Aires, Emecé Editores. Traducción de Ramón Garriga.

IgNACIO DE Loyola (1982): Ejercicios espirituales, en Obras completas. Madrid, Biblioteca de Autores Cristianos. 
Marin, L. (1997): Pascal et Port-Royal, Paris: Presses Universitaires de France.

Morot-Sir, É. (1996): La raison et la grâce selon Pascal, Paris, Presses Universitaires de France.

O'Donell, J. J. (1992): Augustine Confessions (3 vol.), Oxford: Oxford University Press.

Pascal, B. (2004) Pensées, Paris, Gallimard. Édition présentée, établie et annotée par Michel Le Guern.

Pascal, B. (2010): Discurso acerca de las pasiones del amor, México, Fondo de Cultura Económica. Traducción de Raúl Falcó.

Sellier, P. (1979): Pascal et Saint Augustin, Paris, Armand Collin.

Sellier, P. (1999): Port-Royal et la littérature I. Pascal, Paris, Honoré Champion Éditeur.

Villar Ezcurra, A. (2010) "El yo inasible de Pascal frente a la fortaleza del sujeto cartesiano", Isegoría. Revista de filosofía moral y política, 42, pp.265-278.

Villar Ezcurra, A. (2012) "Blaise Pascal, pensar sin límites. Estudio introductorio" en Blaise Pascal, B. Obras completas, Madrid, Editorial Gredos.

Diego I. Rosales Meana

Centro de Investigación Social Avanzada, México

diego.rosales@cisav.org 